\title{
For a Reference Framework of Forest Management at the Service of the Restoration of the Forest Landscapes of the Argan Tree (MOROCCO)
}

\author{
Naggar Mustapha ${ }^{1 *}$, Lahssini Said ${ }^{2}$ and Moukrim Said ${ }^{3}$ \\ ${ }^{1}$ Department of Water and Forests , Ex-Chief of the Forest Management Division, Morocco \\ ${ }^{2}$ Research professor at the National Forestry School of Salé, Morocco \\ ${ }^{3}$ Chief of Forest Resources Service at the Department of Water and Forests, Morocco
}

*Corresponding author: Naggar Mustapha, Department of Water and Forests, Forest Agronomist Engineer, Ex-Chief of the Forest Management Division, Morocco

\begin{abstract}
Summary
The general principles of forest management, while generally known, have shown difficulties in their application to forest ecosystems in arid zones such as the argan forest. Since the early 1990s, the practice of forest management has evolved to better support the multi-functionality of forest areas and the sustainability of their resources. It is a matter of reframing the interventions in the different management units through the adoption of "restorative" activities that aims to strengthen the resilience of these ecosystems. This paper proposes to explore the possibilities of developing a reference system adapted to the restoration requirements of argan ecosystems marked by their vulnerability to global changes. It comes at the right time after the call of Agadir for the restoration of forest ecosystems on the sidelines of the 5th Mediterranean Forest Week held in Morocco (March 2017).

Abstract

The general principles of forest management have been shown to be of application to forest ecosystems in such areas as the argan forest. Since the early 1990s, the practice of forest management has evolved to be more supportive of the multi-functionality of forest areas and the sustainability of their resources. It is a matter of reframing the interventions in the different management units through the adoption of "restorative" activities that enhance the resilience of these ecosystems. This paper proposes to explore the possibilities of developing a global system of knowledge and understanding of argan ecosystems. Mediterranean Forest Week in Agadir - Morocco (March 2017) for the restoration of forest ecosystems.
\end{abstract}

Keywords: Forest management; Ecosystem; Restoration; Argon tree

\section{Introduction}

The argan tree (Argania spinosa (L), Skeels) is a specifically Moroccan endemic species. This forest-fruit and forage tree currently covers nearly 870,000 ha in almost continuous mass in southwestern Morocco, representing about $17 \%$ of the national forest area. Argan ecosystems are characterized by interweaving and interpenetration with various formations and plant species. These ecosystems represent a very important floristic and faunistic richness and where an endemism of plant and animal species is individualized. The rural population living directly and indirectly in forest landscapes is of the order of 3 million inhabitants, through the exercise of usufruct rights: argan oil, firewood and service, pasture, plants aromatic and medicinal, etc. For these vulnerable areas, the argan plantation offers employment opportunities for "green jobs" estimated at more than 2 million working days per year, of which $80 \%$ is devoted to the extraction of argan oil [1].

\section{Forest management context and problem}

Management approaches have undergone improvements in recent decades reflecting the evolution of forest policies adopted for the sustainable management of natural resources. In fact, forest management plans have gone from plans targeting wood production in priority to integrated management plans that take into account the valuation of wood and non-wood forest products and the promotion of the sectors associated with these products. There is a need to integrate other concerns into forest management 
plans that are becoming relevant at the global and national levels; it is essentially the consideration of biodiversity, the effects of climate change, the fight against desertification, the reception of the public, Despite these relatively modest advances in the evolution of forest management approaches, in practice there has been a lack of correspondence between the technical dimension in terms of impact on the restoration of forest ecosystems and the socioeconomic dimension. in relation to the practices practiced in the argan tree. This observation challenges us on the insufficiency of the technical and management capacities often weakly adapted to the context of the argan forest massifs having a principal vocation of protection and to answer to a social demand in goods and services far exceed the productive possibilities of the argan tree [2]. Through this communication, it is sought to develop and consolidate forest management approaches aimed at the restoration of forest ecosystems, especially at the level of argan landscapes. This requires an ecosystem approach that integrates the analysis and treatment of the technical, legislative and institutional aspects necessary for the management of argan forest management plans.

\section{Materials and Methods}

A bibliographic synthesis work has been undertaken at the level of about twenty argan forests totaling an area of 270,000ha and which have been the subject of forest management studies available at the Department of Water and Forests. A critical analysis was carried out on the topics addressed during these studies particularly those relating to socio-economic aspects, forest inventory as well as proposals for development by forest with a presentation of the development case. the argan plantation of Ida $\mathrm{Ou} \mathrm{Zal}$ [3]. In the light of the results of these analyzes, it has been allowed to propose and build a reference system for the conduct of forest ecosystem management studies of the argan tree and which will be presented in the results and discussions section.

\section{Study of the Case of the Argan Plantation of Ida Or Zal}

\section{Analyzes and inventory}

The forest of Ida or Zal occupies an area of nearly 80,000ha. The uses practiced in this arganeraie is at the origin of several productions making it possible to ensure diversified incomes to the local population (77.000 inhabitants) and form the backbone of a system agroforestry typical to this region known as the argan [4]. For this sylvo-pastoral forest, the number of livestock grazing in the forest is 50,000 head, $60 \%$ of which are goats. The average fuelwood consumption from the forest is around 6 tonnes per household per year. The total potential production of Ida or Zal argan oil is estimated at 240,000 liters / year ( 1 to 2.5 liters of oil per family per week), generating an annual turnover of 36 Million of dirhams with an average price of $150 \mathrm{dh}$ per liter. Thus, this forest contributes $45 \%$ overall to the income of rural households [5].

\section{Planning proposals}

The management objectives selected for the Ida Ou Zal forest massif can be summarized as follows: a. Ensure the conservation and development of forest ecosystems by planting argan trees;

b. Promote the development of value chains through incomegenerating actions, particularly that of argan oil;

c. Ensuring the improvement and preservation of biodiversity and the promotion of ecotourism;

For this purpose, the Ida Ou Zal Forest has been subdivided into 265 plots which are considered the smallest forest management units. The grouping and grading allowed to individualize four (4) series of management:
a. Argan tree series (45,300ha),
b. Thuja series $(9,400 \mathrm{ha})$,
c. Green oak series (7,500ha) and
d. Biodiversity Conservation and Enhancement Series $(8,000 \mathrm{ha})$.

In the case of the argan tree series, four silviculture units (management group) are individualized, each grouping the stands at a well-defined stage of development and for appropriate silviculture. These are the regeneration group, the preparation group, the silvopastoral improvement group and a $4^{\text {th }}$ protection and conservation group [6].

a. The regeneration group of 47 plots $(12,500 \mathrm{ha})$ consists of light to scattered stands of argan trees requiring replanting by planting;

b. The Silvopastoral Improvement Group (SPA) with 32 plots (8,600ha) consists of relatively light argan strata close to the douars to meet the growing demand for forage units;

c. The preparation group contains 54 plots $(15,100 \mathrm{ha})$ to be prepared for regeneration during the next development review.

d. For the conservation and protection group contains 33 plots $(9,000 \mathrm{ha})$ to conserve existing stands for as long as possible and to protect basic infrastructure in the Ida or Zal area.

The recommended silviculture system aims to preserve the biodiversity of the ecosystems of this argan tree, the quality of the landscape and the reconstitution of degraded stands. Also, the cultivation rules are based on the application of two principles: the continuity of cover and the preservation of biotopes in the forest.

\section{Results and Discussions}

\section{For a new frame of reference for the management of forest argan ecosystems}

The master plan for the management of forest argan landscapes, the zoning of argan forest landscapes requires consideration of homogeneous management units at two levels:
a. homogeneous eco-physiographic units and
b. potential vocations of the forest area. 
c. Uniform eco-physiographic units of the forest area:

The eco-physiographic units will be defined on the basis of a typology taking into account the occupation and the current use of the soil and edapho-climatic indicators. They are spatial units for decision-making and action, where the same intervention programs can be developed by practicing appropriate silviculture.

For the case of the argan tree, four units will be identified namely:

a) Degraded forest areas where the forest cover has undergone major disturbances: They include degraded forest landscapes with varying degrees of forest cover change, particularly in the lowland argan forest which has been under cultivation.

b) Forest areas to preserve: The areas to be preserved consist mainly of sites of biological and ecological interest (SIBE) which have been taken over as the zone of complete prohibition by the argan tree biosphere reserve (RBA) recognized by the MAB-UNESCO in December 1998.

c) Forest areas at risk: The exploitation of forest resources in these areas involves restrictions, controlled and moderate use, because of the marked fragility of these areas and their sensitivity to desertification and erosion.

d) Forest areas of economic viability: The zones of economic viability present favorable assets for the forest production that is to say of goods and services economically viable and useful for the populations. These areas will be subject to potential logging and silvo-pastoral use and do not pose a risk with fertility levels that allow for satisfactory production.

\section{Potential Vocations of Forest and Rural Space}

The homogeneous units identified will be integrated into the four main lines of action: recover, preserve, control and produce. The results of these analyzes make it possible to identify the management and restoration guidelines for forest argan landscapes. The approach advocated requires taking into account vocations of forest production, multiple production (sylvo-pastoralism, agro sylvo pastoralism and agriculture) and the integration of local populations in the program of restoration of the argan tree [7]. Forest landscapes of argan trees, encompass a natural plural ecosystem, requiring the adoption of an integrated program of preservation and restoration of these environments through the following activities:

a. Promoting a participatory approach based on the consolidation of skills, and local capacities.

b. The integration of development and natural resource management actions by homogeneous zone in order to foster synergy between the different components of the program.

\section{Improvement prospects}

\section{On the technical side}

a. Development of tools allowing the integration of goods and services in the preparation of management plans; b. Elaboration of mechanisms for taking into account the elements of biodiversity and climate change in the proposed silvicultural routes;

c. Development of integration models of social aspects in planning decisions;

d. Design and development of an information system for the monitoring of developments;

\section{At the institutional level}

a. Development of a master plan of development which specifies the orientations to be retained for the argan plantation;

b. Promoting new forms of partnership with community organizations for better management of forest management plans;

c. Integrate in the basic forest training the themes relating to the valuation and conservation of the various resources of the ecosystem: multi-resource management, communication and negotiation techniques.

d. Coordination of research and development programs: restoration of the argan tree, taking into account global changes and valorization of value chains of argan products;

e. Give the managers and managers of the argan tree the environmental economics tools and arguments needed to defend the development proposals.

\section{Conclusion}

The restoration of the multifunctional forest ecosystems of the argan tree can only be achieved through an approach that can reconcile the objectives of preservation and sustainable development of the natural resources associated with these forest areas. This involves the promotion of agro-forestry systems that can integrate ecosystem forest management approaches into the dynamics of territorial development of the argan tree and that has been established as a biosphere reserve since 1998. The global management approach is constantly evolving to better address the problem of restoration of forest landscapes of argan tree, it is to:

a. Better know and assess the state of resources by ecosystem of the argan tree to develop,

b. privilege partnership and contractualization with the stakeholders concerned for the implementation of the prescriptions of the forest management plans, and

c. size the planning units taking the vocation of the environments and the expected objectives.

\section{References}

1. Iufro (2001) Proceedings of the international seminar on cedar silviculture and cork oak. p. 257.

2. Mhirit O (1998) The argan tree, a fruit tree species with multiple uses. Mardaga Editions p. 350.

3. (1999) Synthesis Report of the National Forestry Program. Ministry in Charge of Waters and Forests p. 130. 
4. (2001) Synthesis of the Framework plan of the Arganeraie Biosphere Reserve. Ministry in charge of Waters and Forests p. 120.

5. Naggar M (2017) The forest issue in Morocco and the challenges of territorial governance. European University Editions p. 87.

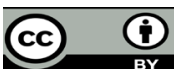

This work is licensed under Creative Commons Attribution 4.0 License

To Submit Your Article Click Here: Submit Article

DOI: 10.32474/CIACR.2019.07.000269
6. Naggar M, Lahsaini S (2017) Forest management and the challenges of restoring forest ecosystems in Morocco. Mediterranean Forest Review 38(1).

7. Naggar M, Mhirit O (2006) Arganeraie a typical course of aride and semi aride Moroccan areas. Drought Review 17(1-2): 314-317.

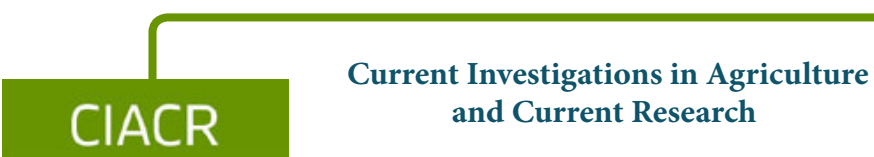

Assets of Publishing with us

- Global archiving of articles

- Immediate, unrestricted online access

- Rigorous Peer Review Process

- Authors Retain Copyrights

- Unique DOI for all articles 